\title{
Caspase Inhibitors Attenuate 1-Methyl-4-Phenylpyridinium Toxicity in Primary Cultures of Mesencephalic Dopaminergic Neurons
}

\author{
James Bilsland,, Sophie Roy, ${ }^{2}$ Steve Xanthoudakis, ${ }^{2}$ Donald W. Nicholson, ${ }^{2}$ Yongxin Han, ${ }^{2}$ Erich Grimm, ${ }^{2}$ \\ Franz Hefti, ${ }^{1}$ and Sarah J. Harper ${ }^{1}$ \\ ${ }^{1}$ Merck, Sharp and Dohme Neuroscience Research Centre, Terlings Park, Harlow, Essex, CM20 2QR, United Kingdom, \\ and ${ }^{2}$ Merck-Frosst Centre for Therapeutic Research, Pointe Claire-Duval, Quebec, H9R 4P8, Canada
}

Parkinson's disease is characterized by a loss of dopaminergic nigrostriatal neurons. This neuronal loss is mimicked by the neurotoxin 1-methyl-4-phenylpyridinium $\left(\mathrm{MPP}^{+}\right)$. $\mathrm{MPP}^{+}$toxicity is mediated through inhibition of mitochondrial complex I, decreasing ATP production, and upregulation of oxygen radicals. There is evidence that the cell death induced by $\mathrm{MPP}^{+}$is apoptotic and that inhibition of caspases may be neuroprotective. In primary cultures of rat mesencephalic dopaminergic neurons, $\mathrm{MPP}^{+}$treatment decreased the number of surviving dopaminergic neurons in the cultures and the ability of the neurons to take up $\left[{ }^{3} \mathrm{H}\right]$ dopamine $\left(\left[{ }^{3} \mathrm{H}\right] \mathrm{DA}\right)$. Caspase inhibition using the broad-spectrum inhibitor benzyloxycarbonyl-Val-AlaAsp-fluoromethylketone (zVAD-fmk) spared MPP ${ }^{+}$-treated dopaminergic neurons and increased somatic size. There was a partial restoration of neurite length in zVAD-fmk-treated cultures, but little restoration of $\left[{ }^{3} \mathrm{H}\right] \mathrm{DA}$ uptake. Peptide inhibitors of caspases 2, 3, and 9, but not of caspase 1, caused significant neuroprotection. Two novel caspase inhibitors were tested for neuroprotection, a broad spectrum inhibitor and a selective caspase 3 inhibitor; both inhibitors increased survival to $>90 \%$ of control. No neuroprotection was observed with an inactive control compound. $\mathrm{MPP}^{+}$treatment caused chromatin condensation in dopaminergic neurons and increased expression of activated caspase 3 . Inhibition of caspases with either zVADfmk or a selective caspase 3 inhibitor decreased the number of apoptotic profiles, but not expression of the active caspase. We conclude that $\mathrm{MPP}^{+}$toxicity in primary dopaminergic neurons involves activation of a pathway terminating in caspase 3 activation, but that other mechanisms may underlie the neurite loss.

Key words: Parkinson's disease; apoptosis; $M P P^{+}$; caspase; neuroprotection; dopaminergic neurons
Parkinson's disease is a neurodegenerative condition characterized by rigidity and akinesia. A major pathological hallmark of Parkinson's disease is the degeneration of nigrostriatal dopaminergic neurons (Marsden, 1990), which is mimicked in vivo by the neurotoxin 1-methyl-4-phenyl-1,2,3,6-tetrahydropyridine (MPTP). The toxicity of MPTP is mediated through the toxic metabolite, 1-methyl-4-phenylpyridinium $\left(\mathrm{MPP}^{+}\right)$. The mechanism by which $\mathrm{MPP}^{+}$kills dopaminergic neurons is unclear. $\mathrm{MPP}^{+}$is known to inhibit mitochondrial complex I, decreasing cellular metabolism and increasing generation of oxygen radicals (Akaneya et al., 1995; Degli, 1998; Schapira, 1998). Evidence has emerged recently that $\mathrm{MPP}^{+}$treatment may lead to apoptosis.

After MPTP or $\mathrm{MPP}^{+}$treatment, apoptotic nuclei have been detected in vivo (Tatton and Kish, 1997) and in vitro (Mochizuki et al., 1994, Dodel et al., 1998; Eberhardt et al., 2000). Transgenic mice overexpressing anti-apoptotic $\mathrm{Bcl}-2$ are resistant to $\mathrm{MPP}^{+}$ toxicity in vitro and MPTP toxicity in vivo (Offen et al., 1998, Yang et al., 1998). Inhibition of caspases, mediators of the apoptotic response, has been reported to prevent $\mathrm{MPP}^{+}$-mediated cell death in vitro (Du et al., 1997; Dodel et al., 1998). Mice overexpressing dominant negative caspase 1 have been shown to be resistant to MPTP toxicity in vivo (Klevenyi et al., 1999), and activation of caspases 3, 8, and 2 has been reported in the substantia nigra of MPTP-treated mice (Yang et al., 1998; Hart-

Received Nov. 14, 2001; revised Nov. 14, 2001; accepted Dec. 18, 2001.

Correspondence should be addressed to James Bilsland, Merck, Sharp and Dohme Neuroscience Research Centre, Terlings Park, Harlow, Essex, CM20 2QR, UK. E-mail: james_bilsland@merck.com.

Copyright $\odot 2002$ Society for Neuroscience $0270-6474 / 02 / 222637-13 \$ 15.00 / 0$ mann et al., 2001; Turmel et al., 2001). Both caspase inhibition and overexpression of inhibitor of apoptosis protein (IAP) have been shown to protect dopaminergic neurons from $\mathrm{MPP}^{+}$in vivo and in vitro (Eberhardt et al., 2000).

Although these data indicate that $\mathrm{MPP}^{+}$toxicity is mediated by caspase activation and subsequent apoptosis, reports conflict regarding the mechanism of $\mathrm{MPP}^{+}$toxicity in vitro and the efficacy of caspase inhibition. Lotharius and coworkers (1999) found no evidence of phosphatidylserine externalization, a marker of apoptosis, after $\mathrm{MPP}^{+}$treatment of mesencephalic neurons, and they reported that the toxicity was not inhibited by treatment with a broad-spectrum caspase inhibitor. Hartmann and coworkers (2001) reported that caspase inhibition potentiated $\mathrm{MPP}^{+}$-mediated cell death in vitro by increasing necrosis, unless neurons were maintained in elevated glucose levels.

Thus, the mechanism of $\mathrm{MPP}^{+}$toxicity in vitro, and the role of caspases, is unclear. In this study we have tested a number of peptide caspase inhibitors for neuroprotective effects against $\mathrm{MPP}^{+}$toxicity in rat mesencephalic dopaminergic neurons in vitro, together with two novel caspase inhibitors and an inactive analog. $\mathrm{MPP}^{+}$-treated dopaminergic neurons show apoptotic profiles and express activated caspase 3. Caspase inhibition restores the number of surviving dopaminergic neurons and increases somatic size and neurite length in these neurons but is less effective in restoring $\left[{ }^{3} \mathrm{H}\right] \mathrm{DA}$ uptake. Broad-spectrum caspase inhibitors caused survival of dopaminergic neurons to $>90 \%$ of untreated control, as did a novel caspase 3 inhibitor. These data suggest that the pathways activated by $\mathrm{MPP}^{+}$in this culture system converge during caspase 3 activation and that 
inhibition of caspase 3 is sufficient to prevent the $\mathrm{MPP}^{+}$mediated death of these neurons.

\section{MATERIALS AND METHODS}

Materials. Pregnant Sprague Dawley rats were purchased from Harlan Seralabs. DMEM, HBSS, and trypsin were purchased from Invitrogen (Paisley, UK). Fetal bovine serum (FBS), mazindol, antibiotic/antimycotic solution, Cy-3-conjugated goat anti-rabbit IgG, extravidin-FITC, and tetramethylrhodamine isothiocynate-conjugated anti-rabbit $\mathrm{IgG}$ were purchased from Sigma-Aldrich Co. (Poole, UK). Benzyloxycarbonyl-ValAla-Asp-fluoromethylketone (zVAD-fmk), benzyloxycarbonyl-Asp(OMe)Glu(OMe)-Val-Asp(OMe)-fluoromethylketone (zDEV D-fmk), benzyloxycarbonyl-Leu-Glu(OMe)-His-Asp(OMe)-fluoromethylketone (zLEHD-fmk), benzyloxycarbonyl-Tyr-Val-Ala-Asp-chloromethylketone (zYVAD-cmk), and the FITC-FragEL apoptosis detection kit were all purchased from Calbiochem/Novabiochem (Nottingham, UK). Hoechst 33342 was purchased from Molecular Probes (Eugene, OR). $\mathrm{MPP}^{+}$iodide was purchased from RBI. Vectastain Elite ABC kits, Vector SG insoluble peroxidase substrate, and normal goat serum were obtained from Vector Laboratories (Peterborough, UK). Rabbit polyclonal anti-tyrosine hydroxylase $(\mathrm{TH})$ antiserum was purchased from the Institut Jacques Boy (Reims, France). Mouse monoclonal anti-TH was purchased from Chemicon. Rabbit anti-cleaved caspase 3 was purchased from New England Biolabs. Sato serum substitute (Bottenstein and Sato, 1979) was made in-house (final concentration in medium: $4.3 \mathrm{mg} / \mathrm{ml}$ bovine serum albumin, $0.77 \mu \mathrm{g} / \mathrm{ml}$ progesterone, $20 \mu \mathrm{g} / \mathrm{ml}$ putrescine, $0.49 \mu \mathrm{g} / \mathrm{ml}$ L-thyroxine, $0.048 \mu \mathrm{g} / \mathrm{ml}$ selenium, and $0.42 \mu \mathrm{g} / \mathrm{ml}$ tri-iodo-thyronine). All components of this serum substitute were purchased from Sigma-Aldridge Co. $\left[{ }^{3} \mathrm{H}\right] \mathrm{DA}$ was purchased from Amersham Biosciences.

Mesencephalic cultures. The ventral mesencephalon was dissected from $14 \mathrm{~d}$ gestation Sprague Dawley rat embryos (Harlan Ltd.). Tissues were incubated with $0.25 \%$ trypsin in $\mathrm{HBSS}$ for $20 \mathrm{~min}$ at $37^{\circ} \mathrm{C} / 5 \% \mathrm{CO}_{2}$, then mechanically dissociated using a flame-polished Pasteur pipette. For cell survival assays, cells were plated at a density of 200,000 cells per well onto poly-D-lysine-coated eight-well chamber slides (Invitrogen) in DMEM supplemented with $10 \%$ FBS and $1 \%$ antibiotic/antimycotic solution and incubated for $2 \mathrm{hr}$. This medium was then aspirated and replaced with DMEM supplemented with Sato serum substitute. Cultures were incubated for a further $5 \mathrm{~d}$ before experimental procedures.

Treatment with compounds. zVAD-fmk, zDEVD-fmk, zLEHD-fmk, and zYVAD-cmk were prepared in DMEM supplemented with Sato and added to the cultures $15 \mathrm{~min}$ before $\mathrm{MPP}^{+}$exposure at concentrations ranging from 0.1 to $300 \mu \mathrm{M}$. Each compound was added to four independent wells at each concentration tested. Control cultures were returned to DMEM/Sato in the absence of compounds. $\mathrm{MPP}^{+}$iodide was prepared at a concentration of $110 \mu \mathrm{M}$, then added directly to the medium in the wells to give a final concentration in each well of $10 \mu \mathrm{M}$; control cultures were treated with tissue culture medium in the absence of $\mathrm{MPP}^{+}$. Cultures were incubated at $37^{\circ} \mathrm{C} / 5 \% \mathrm{CO}_{2}$ for a further $48 \mathrm{hr}$, then were fixed using $4 \%$ paraformaldehyde in PBS and immunostained for TH.

Determination of TH-immunoreactive neuronal survival. To determine the number of surviving dopaminergic neurons, immunocytochemistry was performed using a rabbit polyclonal antibody raised against $\mathrm{TH}$. Nonspecific binding sites were blocked using $10 \%$ normal goat serum in PBS, then primary antibody was added at $4^{\circ} \mathrm{C}$ overnight. The next day, the cells were washed and treated with biotin-conjugated goat anti-rabbit IgG for $1 \mathrm{hr}$, followed by peroxidase-conjugated avidin-biotin complex, both made up from the Vectastain Elite ABC kit according to the manufacturer's instructions. Staining was visualized using Vector SG insoluble peroxidase substrate according to the manufacturer's instructions. After staining, the gaskets were removed from the chamber slides, and the slides were mounted using aqueous mountant. Slides were blinded by another investigator before quantification of TH-immunoreactive cell survival.

To determine TH-immunoreactive cell survival, cells were observed under transmitted light on a Zeiss Axiovert inverted microscope using a $10 \times$ objective. Counts were made of all the TH-immunoreactive cells present in each well. The culture conditions described here typically produce a yield of $\sim 0.5-1 \%$ TH-immunoreactive cells, or $\sim 1500$ cells in a control well. For each compound tested, three independent experiments were performed, each consisting of four independent wells. Each compound was also tested in the absence of $\mathrm{MPP}^{+}$to detect any nonspecific neuroprotective or toxic effects (data not shown).

$\left[{ }^{3} H\right] D A$ uptake assays. Primary cultures of mesencephalic dopaminergic neurons were prepared as described above and plated at a density of
$2.5 \times 10^{5}$ cells per well in poly-D-lysine-coated 48 -well tissue culture clusters. Cultures were maintained for $5 \mathrm{~d}$ at $37^{\circ} \mathrm{C} / 5 \% \mathrm{CO}_{2}$ in DMEM supplemented with Sato. After $5 \mathrm{~d}$, medium was aspirated and replaced with either $\mathrm{MPP}^{+}$at concentrations ranging from 0.01 to $100 \mu \mathrm{M}$ or with zVAD-fmk at concentrations ranging from 1 to $300 \mu \mathrm{M}$ in the presence of 1 or $10 \mu \mathrm{M} \mathrm{MPP}{ }^{+}$. In both cases compounds were prepared in DMEM/ Sato. Four independent wells were treated for each condition in each experiment; three independent experiments were performed for each data point. Cultures were incubated for a further $48 \mathrm{hr}$, then $\left[{ }^{3} \mathrm{H}\right] \mathrm{DA}$ uptake was evaluated.

To determine $\left[{ }^{3} \mathrm{H}\right] \mathrm{DA}$ uptake, the medium was aspirated from each well and replaced with DMEM supplemented with $5.6 \mathrm{~mm}$ glucose, 1.3 $\mathrm{mm}$ EDTA, $0.2 \mathrm{mg} / \mathrm{ml}$ ascorbic acid, and $0.5 \mu \mathrm{Ci} / \mathrm{ml}\left[{ }^{3} \mathrm{H}\right] \mathrm{DA}$. Control cultures were treated with the above medium with the addition of the dopamine uptake blocker mazindol $(10 \mu \mathrm{M})$. Cultures were incubated for $30 \mathrm{~min}$, then washed twice and lysed using $95 \%$ ethanol at $37^{\circ} \mathrm{C}$ for 30 min. Lysates were transferred to aqueous scintillant, and the activity was quantified. Results were expressed as percentage of untreated control culture response.

Visualization of apoptotic nuclei. For determination of apoptotic nuclei, cells were plated as described above into eight-well chamber slides. After $5 \mathrm{~d}$ in vitro, the medium was aspirated and replaced with DMEM/Sato or zVAD-fmk $300 \mu \mathrm{M}$. Cultures were returned to the incubator for $15 \mathrm{~min}$, after which $\mathrm{MPP}^{+}$iodide was added as described above to give a final concentration in each well of $10 \mu \mathrm{M}$. Control cultures were treated with DMEM/Sato only. Cultures were fixed using $4 \%$ paraformaldehyde at 24 and $48 \mathrm{hr}$ after $\mathrm{MPP}^{+}$exposure and immunostained for TH. This was followed by determination of apoptotic nuclei using the nuclear stain Hoechst 33342 to evaluate chromatin condensation.

Quantification of somatic area and neurite length. Microcomputer imaging device (MCID) image analysis (Brock University, Ontario, Canada) was used to evaluate the somatic area of TH-immunoreactive neurons. Area quantification was made from dopaminergic neurons in one experiment, from untreated control cultures, from cultures treated with $10 \mu \mathrm{M}$ $\mathrm{MPP}^{+}$for $48 \mathrm{hr}$, and from cultures treated with $10 \mu \mathrm{M} \mathrm{MPP}{ }^{+}$in the presence of 100 or $300 \mu \mathrm{M}$ zVAD-fmk. One hundred cells were measured from random fields of view throughout each of four wells for each treatment group. To quantify area in micrometers squared, the image analysis system was first calibrated in micrometers using a graticule. The area of immunostained soma were then established using the Autoscan tool. For each neuron, a control density was set outside the area of the stained soma; the stained area of the soma was then established. Neurites were excluded from each measurement. Mean areas for soma within each area were then established, and the results were presented as the mean area across four wells.

For neurite length measurements, MCID image analysis was used to quantify the length of the longest neurite for each of $100 \mathrm{TH}$ immunoreactive neurons in four wells per treatment group. The image analysis system was calibrated as described above. Neurite length measurements were taken from control cultures, cultures exposed to $10 \mu \mathrm{M}$ $\mathrm{MPP}^{+}$for $48 \mathrm{hr}$, or cultures exposed to $10 \mu \mathrm{M} \mathrm{MPP}{ }^{+}$in the presence of $300 \mu \mathrm{M}$ zVAD-fmk. To determine neurite length, a sample tool was used to draw manually along the length of the longest visible neurite. Results were expressed both as mean neurite length for each group and as a percentage of cells with only rudimentary processes; rudimentary processes were defined as being $\leq 10 \mu \mathrm{m}$ in length.

Statistical analyses. All statistical analyses that were performed used one-way ANOVA followed by Dunnett's test comparing all groups with cultures treated with $10 \mu \mathrm{M} \mathrm{MPP}{ }^{+}$alone; for control $\mathrm{MPP}^{+}$experiments, all groups were compared with untreated control results. Significance was reached at $p<0.05$.

\section{RESULTS}

\section{Toxic effects of MPP ${ }^{+}$on dopaminergic neurons}

$\mathrm{MPP}^{+}$was added at concentrations ranging from 0.001 to $100 \mu \mathrm{M}$ to primary cultures of mesencephalic dopaminergic neurons (Fig. 1). Significant decreases in the number of $\mathrm{TH}$-immunoreactive neurons were observed with $\mathrm{MPP}^{+}$concentrations of $0.1 \mu \mathrm{M}$ and above. At $10 \mu \mathrm{M}, \mathrm{MPP}^{+}$reduced the number of surviving $\mathrm{TH}$ immunoreactive neurons to $\sim 50 \%$ of control (Fig. $1 A$ ), and this concentration was selected for further experiments. $\mathrm{MPP}^{+}$was more potent at decreasing $\left[{ }^{3} \mathrm{H}\right] \mathrm{DA}$ uptake than at decreasing the number of $\mathrm{TH}$-immunoreactive neurons, reflecting the loss of 

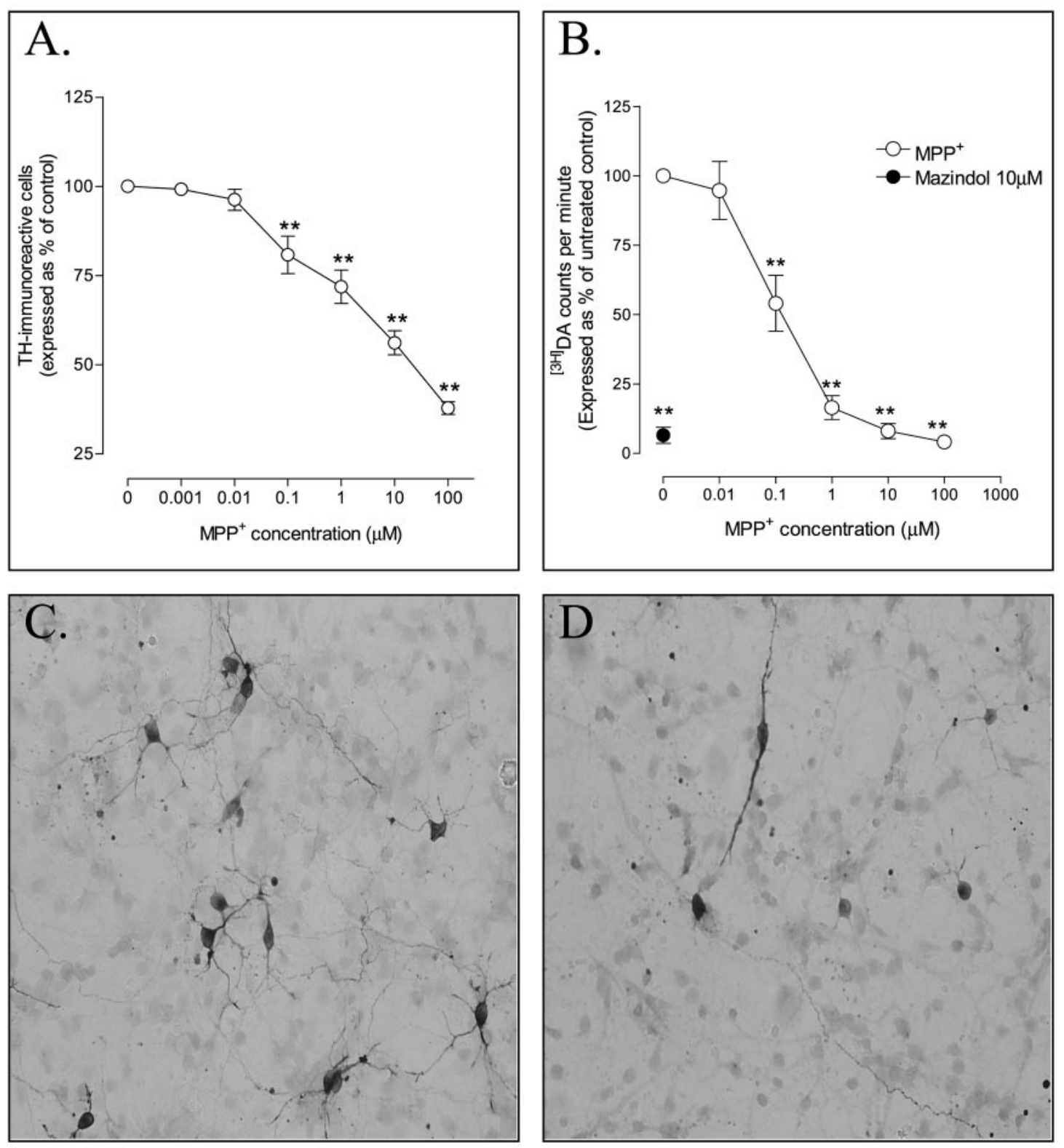

Figure 1. Effects of $\mathrm{MPP}^{+}$on survival $(A)$ and $\left[{ }^{3} \mathrm{H}\right] \mathrm{DA}$ uptake $(B)$ in primary cultures of mesencephalic dopaminergic neurons. MPP ${ }^{+}$was added at concentrations ranging from 0.01 to $100 \mu \mathrm{M}$ for $48 \mathrm{hr}$. Cultures were then either fixed and immunostained for TH, and the surviving TH-immunoreactive cells were counted, or $\left[{ }^{3} \mathrm{H}\right] \mathrm{DA}$ uptake was assayed. Data shown in each case are the mean \pm SEM of three independent experiments and are expressed as percentage of untreated control cultures ${ }^{* *} p<0.01$; established by one-way ANOVA followed by Dunnett's test). Representative photomicrographs of control $(C)$ or $10 \mu \mathrm{M} \mathrm{MPP}^{+}$-treated $(D) \mathrm{TH}$-immunoreactive neurons are shown. Cultures were treated for $48 \mathrm{hr}$, then fixed and immunostained for TH.

dopamine transporter sites on the neurite terminals. Again, significant decreases were observed at $0.1 \mu \mathrm{M} \mathrm{MPP}^{+}$and above, but the response was decreased to $\sim 20 \%$ of control with $\mathrm{MPP}^{+}$concentrations of $1 \mu \mathrm{M}$ and above. Photomicrographs of control cultures (Fig. 1C) and cultures treated with $10 \mu \mathrm{M}$ $\mathrm{MPP}^{+}$for $48 \mathrm{hr}$ (Fig. 1D) show a loss of dopaminergic neurons in the $\mathrm{MPP}^{+}$-treated cultures. The cell bodies of the $\mathrm{MPP}^{+}$treated $\mathrm{TH}$-immunoreactive neurons are also smaller, and there are fewer neurites.

\section{The broad-spectrum caspase inhibitor zVAD-fmk protects dopaminergic cell bodies against MPP ${ }^{+}$ toxicity but does not restore $\left[{ }^{3} \mathrm{H}\right] \mathrm{DA}$ uptake}

To determine the role of caspases in mediating toxicity of $\mathrm{MPP}^{+}$, we tested the broad-spectrum caspase inhibitor zVAD-fmk for neuroprotective effects. Figure 2 shows the effects of zVAD-fmk on the toxicity induced by $10 \mu \mathrm{M} \mathrm{MPP}{ }^{+}$. Treatment of cultures with $10 \mu \mathrm{M} \mathrm{MPP}^{+}$resulted in a loss of $\sim 50 \% \mathrm{TH}$-immunoreactive neurons in the cultures; zVAD-fmk treatment resulted in a concentration-dependent sparing of these neurons, with the maximal effect restoring dopaminergic neuronal number to $>90 \%$ of control cultures (Fig. 2A). Photomicrographs of these cultures are shown in Figure $2 C-E$. Control cultures are shown in Figure $2 C$; Figure 2, $D$ and $E$, shows cultures treated with $10 \mu \mathrm{M} \mathrm{MPP}^{+}$and $300 \mu \mathrm{M} \mathrm{zVAD}$-fmk plus $10 \mu \mathrm{M} \mathrm{MPP}^{+}$, respectively. The cultures treated with $\mathrm{MPP}^{+}$alone have reduced numbers of dopaminergic neurons, and those surviving neurons have smaller cell bodies. Speckled staining is apparent around the neurons, which may reflect the remains of degenerated neurites. In the cultures 

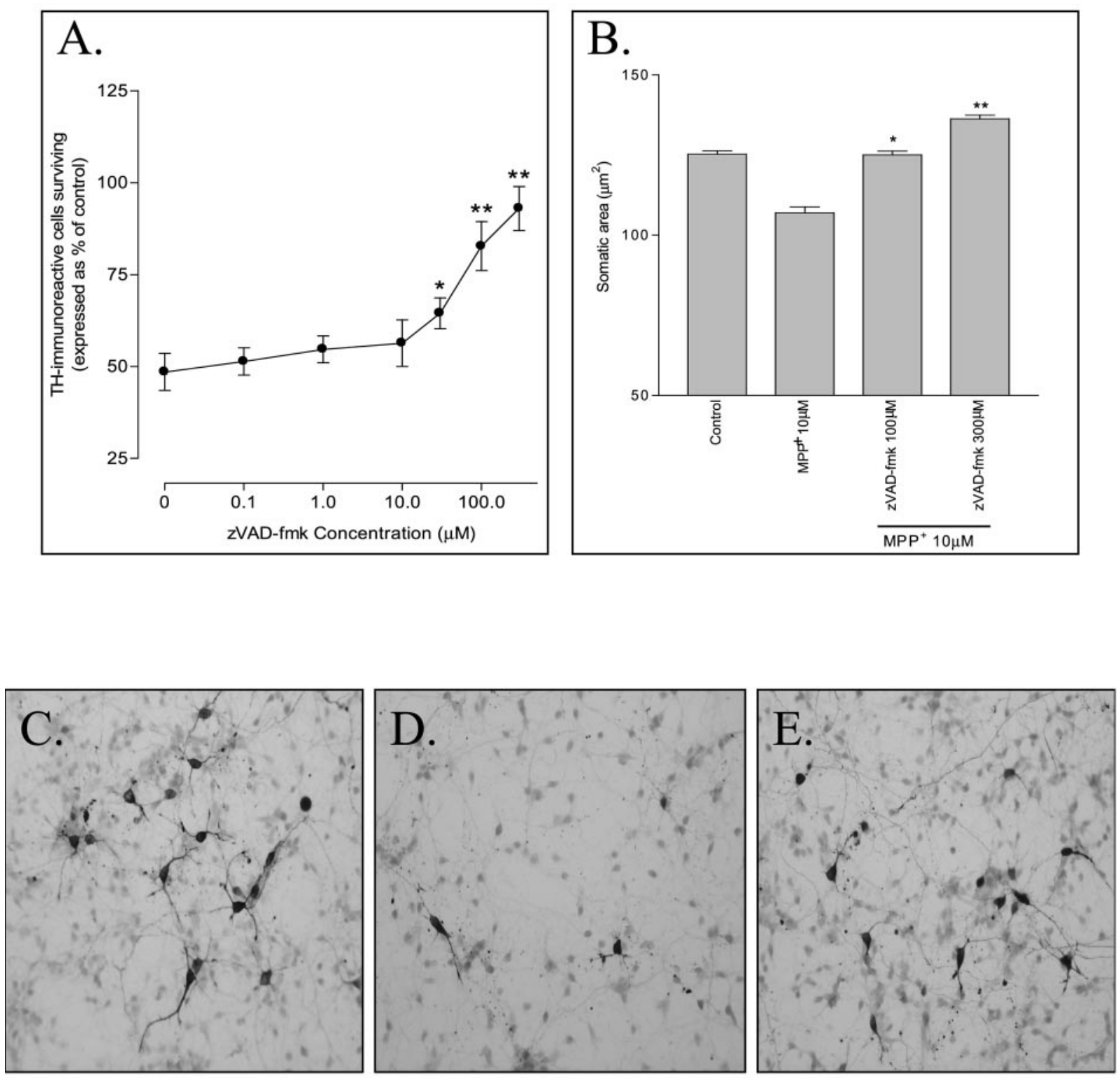

Figure 2. $\mathrm{zVAD}$-fmk attenuates $10 \mu \mathrm{M} \mathrm{MPP}{ }^{+}$toxicity and increases somatic size in mesencephalic dopaminergic neurons. For survival quantification $(A)$, cultures were exposed to $10 \mu \mathrm{M} \mathrm{MPP}{ }^{+}$for $48 \mathrm{hr}$ in the presence of various zVAD-fmk concentrations. Cultures were then fixed and immunostained for TH. Slides were blinded, and TH-immunoreactive cells were counted. Data points shown are from three independent experiments, each consisting of four independent wells, and are expressed as percentage of untreated control cultures ${ }^{*} p<0.05,{ }^{*} p<0.01$; established by one-way ANOVA followed by Dunnett's test). Somatic size measurements $(B)$ were made from each of four wells from one representative experiment. Random fields of view were visualized using MCID image analysis, and densitometry was used to establish the area occupied by the soma of TH-immunoreactive neurons. One hundred cells per well were measured for each data point. Photomicrographs of control $(C), 10 \mu \mathrm{M} \mathrm{MPP}{ }^{+}$-treated $(D)$, and $10 \mu \mathrm{M} \mathrm{MPP}^{+}-$and $300 \mu \mathrm{M}$ zVAD-fmk-treated $(E)$ mesencephalic cultures are shown. Cultures were immunostained for TH, and representative photomicrographs were taken.

treated with both $\mathrm{MPP}^{+}$and zVAD-fmk, there is a restoration of cell number; those neurons remaining have larger cell bodies, and a restoration of neurite number can also be seen, although some speckled staining is also apparent that may reflect a loss or remodeling of neurites.

Quantification of the somatic area of the dopaminergic neurons is shown in Figure $2 B$. Treatment with $10 \mu \mathrm{M} \mathrm{MPP}^{+}$resulted in a significant decrease in the somatic area of the surviving $\mathrm{TH}-$ immunoreactive neurons. This decrease in somatic area was attenuated by treatment with zVAD-fmk at 100 and $300 \mu \mathrm{M}$. At 300 $\mu \mathrm{M}$ zVAD-fmk, the somatic area was significantly greater than that observed in control cultures. The effects of zVAD-fmk on $\mathrm{MPP}^{+}$-mediated neurite loss and the decrease in $\left[{ }^{3} \mathrm{H}\right] \mathrm{DA}$ uptake are shown in Figure 3. To establish whether caspase inhibition could increase $\left[{ }^{3} \mathrm{H}\right] \mathrm{DA}$ uptake in $\mathrm{MPP}^{+}$-treated primary mesencephalic cultures, zVAD-fmk was coadministered with $\mathrm{MPP}^{+}$ concentrations of either 1 or $10 \mu \mathrm{M}$ (Fig. 3A). zVAD-fmk was tested at concentrations ranging from 1 to $300 \mu \mathrm{M}$. The results for both $\mathrm{MPP}^{+}$concentrations show a significant increase in $\left[{ }^{3} \mathrm{H}\right] \mathrm{DA}$ uptake only with a zVAD-fmk concentration of $300 \mu \mathrm{M}$. The increase observed was relatively small in comparison with the increases observed with counts of TH-immunoreactive neurons, indicating that those neurons spared by caspase inhibition may be compromised in their ability to take up $\left[{ }^{3} \mathrm{H}\right] \mathrm{DA}$. This limited effect may be mediated by degeneration of neurites in the dopaminergic neurons. $\mathrm{MPP}^{+}$treatment causes a marked decrease in 

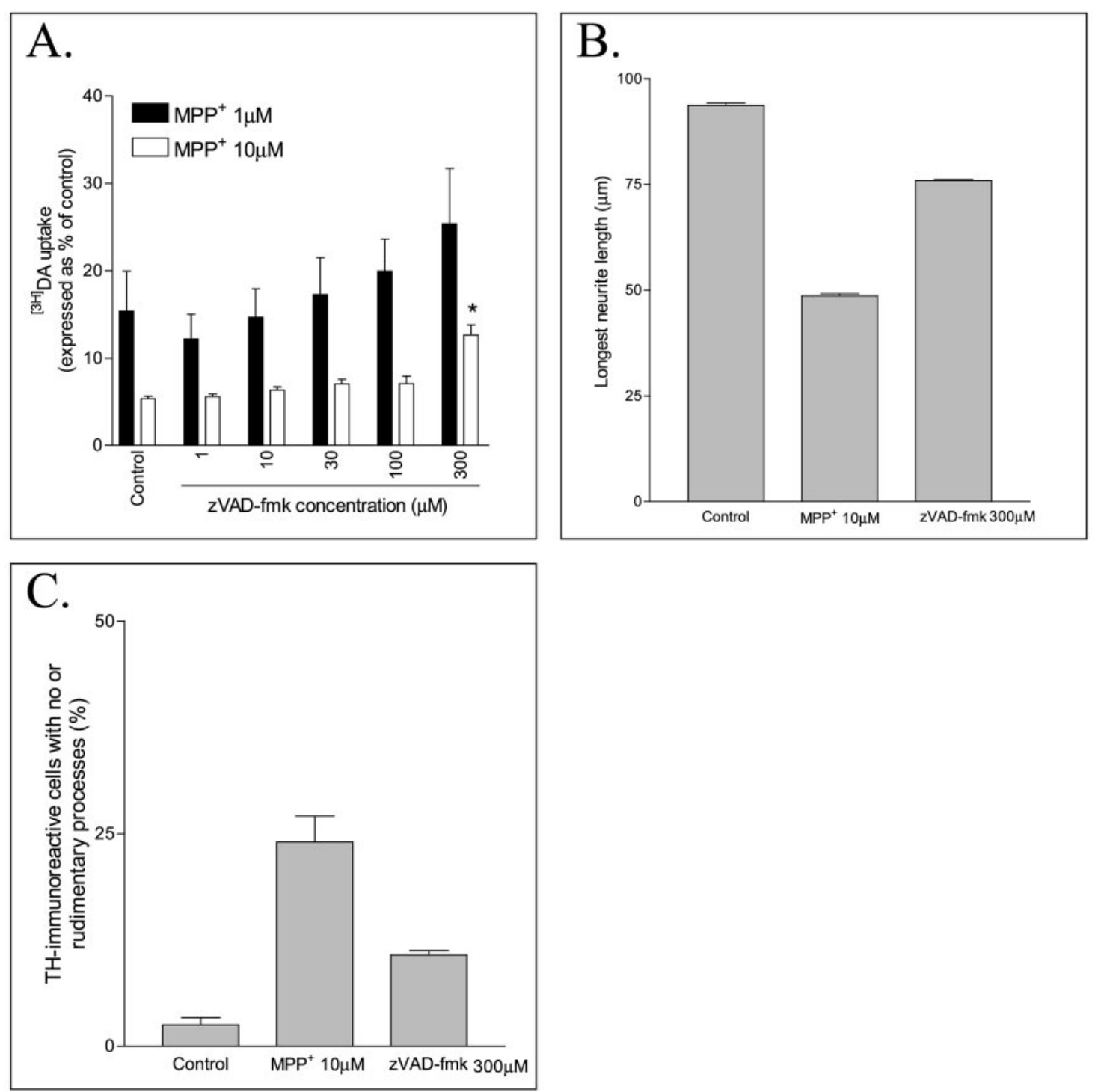

Figure 3. Effects of zVAD-fmk on $\left[{ }^{3} \mathrm{H}\right] \mathrm{DA}$ uptake in primary mesencephalic dopaminergic neurons exposed to 1 or $10 \mu \mathrm{M} \mathrm{MPP}^{+}$and effects of 300 $\mu \mathrm{M}$ zVAD-fmk treatment on neurite length of dopaminergic neurons. For $\left[{ }^{3} \mathrm{H}\right] \mathrm{DA}$ uptake assays (Fig. $3 A$ ), cultures were exposed to 1 or $10 \mu \mathrm{M}$ MPP ${ }^{+}$ in the presence of various concentrations of zVAD-fmk for $48 \mathrm{hr}$, and then the ability of the cells to take up [ ${ }^{3} \mathrm{H}$ ]DA was assayed. Each data point is the mean \pm SEM of three independent experiments, each consisting of four independent wells, and is expressed as percentage of untreated control cultures $\left({ }^{*} p<0.05,{ }^{* *} p<0.01\right.$; established by one-way ANOVA followed by Dunnett's test). Neurite length measurements were made from $\mathrm{TH}$-immunoreactive neurons in control cultures, cultures exposed to $10 \mu \mathrm{M} \mathrm{MPP}{ }^{+}$for $48 \mathrm{hr}$, and cultures treated for $48 \mathrm{hr}$ with $\mathrm{MPP}{ }^{+}$and $300 \mu \mathrm{M}$ zVAD-fmk. MCID image analysis was used to quantify the length of the longest neurite in each of $100 \mathrm{TH}$-immunoreactive neurons in four independent wells per treatment group. $B$ shows the mean neurite length of TH-immunoreactive neurons. $C$ shows the percentage of TH-immunoreactive cells in each treatment group with no, or only rudimentary, neurites; this was defined as a longest process of $<10 \mu \mathrm{m}$ in length.

neurite length, which is only partially restored by zVAD-fmk treatment (Fig. $3 B$ ). Similarly, $\mathrm{MPP}^{+}$caused an increase in the percentage of neurons with no or rudimentary processes (Fig. $3 C$ ), and this was only partially restored by $300 \mu \mathrm{M} \mathrm{zVAD}-$ fmk. Thus, the limited effects of zVAD-fmk in restoring $\left[{ }^{3} \mathrm{H}\right] \mathrm{DA}$ uptake are likely to be attributable to a degeneration of processes and thus of dopamine transporter sites.

\section{Peptide inhibitors of caspases 2, 3, and 9, but not of caspase 1 , partially protect dopaminergic neurons from MPP ${ }^{+}$toxicity}

The effects of a range of peptide inhibitors based on the preferred cleavage sites of specific caspases are shown in Figure 4. Four specific inhibitors were tested: zDEVD-fmk, zVDVAD-fmk,
zLEHD-fmk, and zYVAD-cmk. These inhibitors are based on the cleavage sites of caspases 3, 2, 9, and 1, respectively, and act by binding to and inhibiting the respective enzymes. Although zVDVAD-fmk is an inhibitor based on the preferred cleavage site for caspase 2, it is unlikely to be absolutely specific for caspase 2 . The presence of an Asp residue in the P4 position of the inhibitor is a requirement for peptide inhibitors of caspases 3 and 7, and the VDVAD sequence has also been shown to inhibit these enzymes (Thornberry et al., 1997). Thus, the neuroprotection observed with this inhibitor may be attributable in part to an inhibition of caspase 3. Neither zLEHD-fmk nor zYVAD-cmk is likely to significantly inhibit caspase 3-like proteases; neither of these sequences has the required Asp in the P4 position. The 

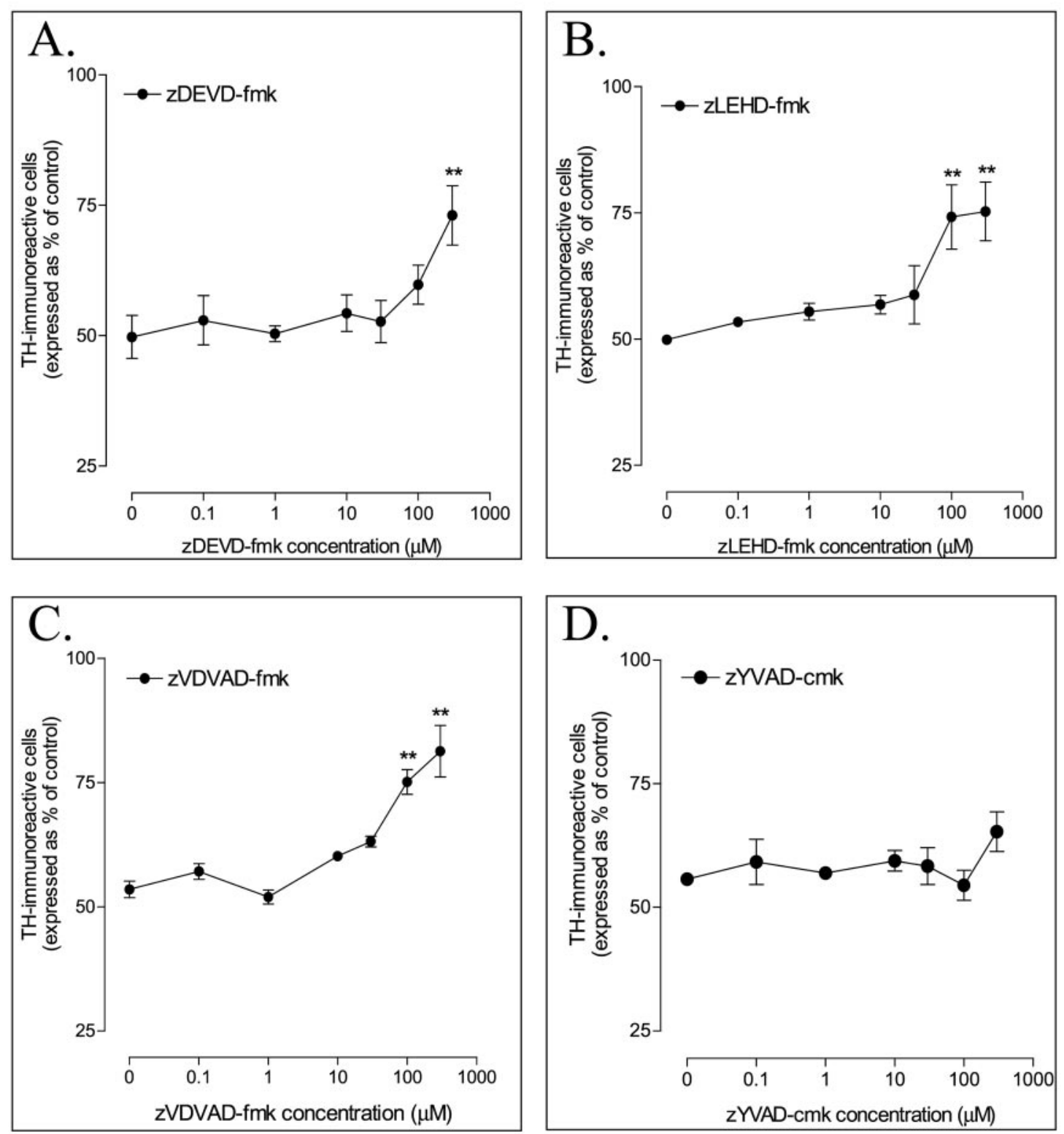

Figure 4. Effects of peptide caspase inhibitors on survival of $\mathrm{TH}$-immunoreactive neurons after $10 \mu \mathrm{M} \mathrm{MPP}^{+}$treatment. Primary cultures of mesencephalic dopaminergic neurons were exposed to $10 \mu \mathrm{M} \mathrm{MPP}{ }^{+}$for $48 \mathrm{hr}$ in the presence of zDEVD-fmk $(A)$, zLEHD-fmk $(B)$, zVDVAD-fmk $(C)$, or zYVAD-cmk $(D)$. Cultures were fixed and immunostained for TH. Slides were then blinded, and the number of surviving TH-immunoreactive neurons was counted. Each data point represents the mean \pm SEM of three independent experiments, each consisting of four independent wells, and is expressed as percentage of untreated control cultures $\left(*^{*} p<0.01\right.$; established by one-way ANOVA followed by Dunnett's test).

YVAD sequence is $\sim 10,000$-fold more selective for caspase 1 than for caspase 2,3 , or 7 and $\sim 1000$-fold more selective for caspase 1 than for caspase 9 (Garcia et al., 1998). The LEHD sequence does resemble the cleavage sites of caspases 4 and 5 ; thus there may be some inhibition of these caspases.

Concentration-dependent increases were observed with three of the inhibitors, zDEVD-fmk (caspase 3), zLEHD-fmk (caspase 9), and zVDVAD-fmk (caspase 2) (Fig. 5A-C), but no significant increases were observed with the caspase 1 inhibitor zYVAD-cmk (Fig. 5D). Significant increases in TH-immunoreactive cell number were observed with zLEHD-fmk and zVDVAD-fmk concentrations of $100 \mu \mathrm{M}$ and above. The caspase 3 inhibitor zDEVDfmk caused significant increases in dopaminergic neuronal survival only at $300 \mu \mathrm{M}$, whereas no significant increases were observed with zYVAD-cmk at any concentration tested.

\section{Effects of novel caspase inhibitors on survival of mesencephalic dopaminergic neurons exposed to $\mathrm{MPP}^{+}$}

Two novel inhibitors of caspases were tested for neuroprotective effects in dopaminergic neurons exposed to $10 \mu \mathrm{M} \mathrm{MPP}{ }^{+}$: M-920, a nonspecific inhibitor of caspases, and M-791, a selective caspase 3 inhibitor. M-725, an inactive analog of M-920, was also tested. These inhibitors are described in a model of sepsis by Hotchkiss and coworkers (2000). The results of these experiments are shown in Figure 5A. Both of the active caspase inhibitors caused significant increases in the number of surviving TH-immunoreactive neurons. Significant neuroprotection was observed with M-920 concentrations of $10 \mu \mathrm{M}$ and above; at concentrations of 10 $\mu \mathrm{M}$ and above, the survival was similar to that observed in untreated control cultures. Treatment of dopaminergic neurons 


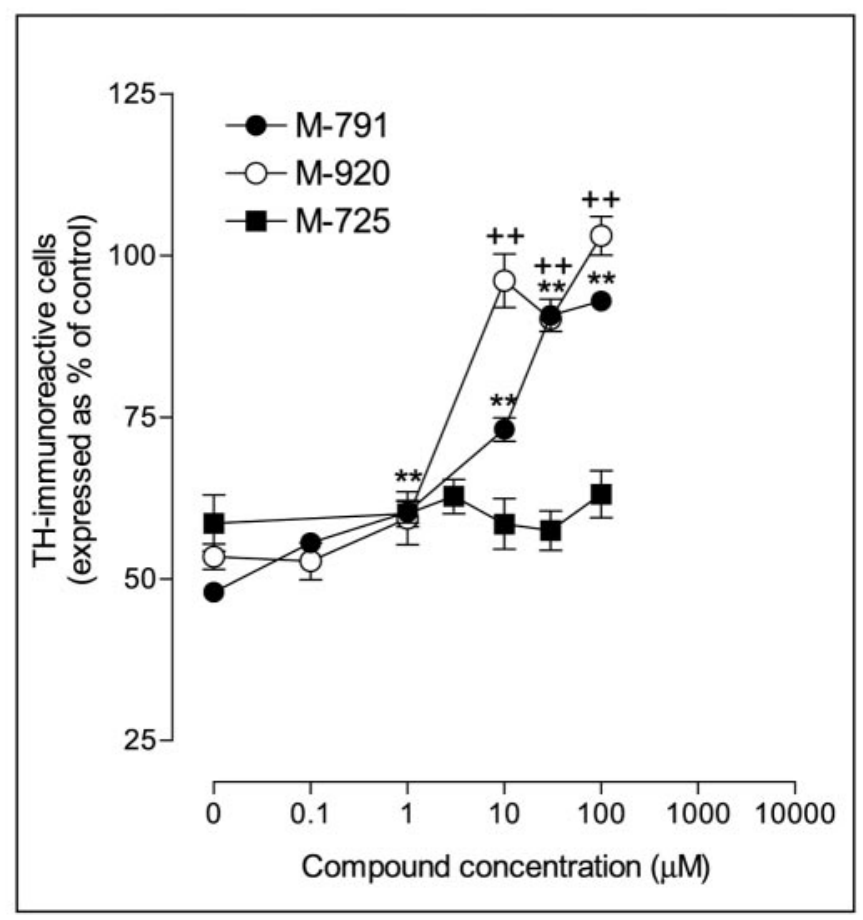

Figure 5. Effects of novel caspase inhibitors on survival of dopaminergic neurons treated with $\mathrm{MPP}^{+}$. Two novel caspase inhibitors were tested for survival-promoting effects in primary cultures of dopaminergic neurons, M-920 and M-791, together with an inactive analog, M-725. Compounds were coadministered with $10 \mu \mathrm{M} \mathrm{MPP}{ }^{+}$for $48 \mathrm{hr}$, and then surviving TH-immunoreactive cells were quantified. Results shown are the mean \pm SEM of four independent wells per treatment group (M-791 response, ${ }_{* *}^{*} p<0.01 ; \mathrm{M}-920$ response, ${ }^{++} p<0.01$; both established by one-way ANOVA followed by Dunnett's test).

with M-791 caused significant neuroprotection at concentrations of $1 \mu \mathrm{M}$ and above; the maximal response observed with this inhibitor increased the number of surviving $\mathrm{TH}$-immunoreactive neurons to $>90 \%$ of untreated control. The significant neuroprotective effects that were observed with M-791 at $1 \mu \mathrm{M}$ indicate that the neuroprotection is likely to be mediated by inhibition of caspase 3-like proteases. The survival response with this caspase 3 inhibitor is considerably higher than that observed with zDEVD-fmk, the peptidergic caspase 3 inhibitor, which might indicate limited cell permeability of the peptide caspase inhibitor. The magnitude of the survival effect of M-791 is equivalent to the effects observed with both zVAD-fmk and M-920, the broad spectrum caspase inhibitors. This indicates that inhibition of caspase 3 alone is sufficient to prevent almost all the toxicity of $\mathrm{MPP}^{+}$in this culture system. When cultures were treated with the inactive compound M-725, no neuroprotective effects were observed at any of the concentrations tested.

With regard to the specificity of the inhibitors, M-920 is reported to have an $\mathrm{IC}_{50}$ value of $0.002 \mu \mathrm{M}$ for caspase 3 in sepsis models and submicromolar $\mathrm{IC}_{50}$ values for caspases $1,4,7$, and 8 . The $\mathrm{IC}_{50}$ values for caspases 5 and 6 are 2 and $1.5 \mu \mathrm{M}$, respectively. M-791 has an $\mathrm{IC}_{50}$ value of $0.008 \mu \mathrm{M}$ for caspase 3 and 0.23 $\mu \mathrm{M}$ for caspase 7 in the sepsis model; the $\mathrm{IC}_{50}$ for caspase 8 is 4 $\mu \mathrm{M}$, and for other caspases it is in the mid-micromolar range (Hotchkiss et al., 2000). $\mathrm{IC}_{50}$ values on a range of caspases and in two whole-cell in vitro models for these three compounds are shown in Table 1.
Table 1. $\mathrm{IC}_{50}$ values for novel caspase inhibitors for various caspases, together with the $\mathrm{IC}_{50}$ values obtained in whole-cell apoptosis assays in cerebellar granule neurons (CGN) and hNT-2 cells

\begin{tabular}{clll} 
& \multicolumn{2}{l}{ Cell free assays } & \\
\cline { 2 - 3 } & M-920 & M-791 & M-725 \\
\hline Caspase & & & \\
1 & 0.01 & 11 & 15 \\
2 & $>50$ & $>450$ & \\
3 & 0.002 & 0.008 & 45 \\
7 & 0.02 & 0.23 & $>100$ \\
8 & 0.04 & 4 & 68 \\
9 & $>50$ & $>450$ & \\
Cell type & Whole cell apoptosis $\mathrm{IC}_{50}$ & \\
\hline hNT2 & $0.12 \mu \mathrm{M}$ & $0.49 \mu \mathrm{M}$ & \\
$1^{\circ}$ mCGN & $0.2 \mu \mathrm{M}$ & $1.0 \mu \mathrm{M}$ & \\
\hline
\end{tabular}

M-920 potently inhibits a number of members of the caspase family, whereas M-791 is a potent inhibitor of caspase 3 and also inhibits caspase 7. M-725 has little potency at any caspase tested. $\mathrm{IC}_{50}$ values presented are micromolar.

\section{$\mathrm{MPP}^{+}$causes apoptotic features and activated caspase 3 expression in degenerating dopaminergic neurons; effects of caspase inhibition}

Nuclear morphology was assessed in dopaminergic neurons after $\mathrm{MPP}^{+}$exposure to determine whether the induced cell death was apoptotic. Photomicrographs of mesencephalic cultures stained for TH and counterstained with Hoechst 33342 to visualize nuclei are shown in Figure 6. TH-immunoreactive neurons are stained green, and Hoechst stained nuclei fluoresce blue. Double exposures were also taken to confirm localization of TH-immunoreactive cell nuclei. $\mathrm{TH}$-immunoreactive neurons are shown in Figure 6, $A, D$, and $F$, Hoechst 33342-stained nuclei are shown in Figure $6, B, E$, and $H$, and double-exposed images to show colocalization are shown in Figure $6, C, F$, and $I$. Figure $6 A-C$ shows control cultures. TH-immunoreactive neurons have large cell bodies and extensive neurites; the nuclear morphology of these neurons shows no chromatin condensation, illustrated by the yellow arrows. Figure $6 D-F$ photomicrographs are of a field of view from cultures exposed to $10 \mu \mathrm{M} \mathrm{MPP}{ }^{+}$for $48 \mathrm{hr}$. Within the field, a number of degenerating $\mathrm{TH}$-immunoreactive neurons can be observed (white arrows). The nuclei of these neurons show chromatin condensation when stained with Hoechst 33342, a characteristic feature of apoptosis. Also within the well are a number of $\mathrm{TH}$-immunoreactive neurons that do not appear to have degenerated; the nuclei of these neurons do not show chromatin condensation (yellow arrow). Figure $6 G-I$ shows cultures exposed to $10 \mu \mathrm{M} \mathrm{MPP}{ }^{+}$for $48 \mathrm{hr}$ in the presence of $300 \mu \mathrm{M}$ zVAD-fmk. The TH-immunoreactive neurons within the culture do not appear to have degenerated, and their nuclei do not show chromatin condensation (yellow arrow). Also within each well, there is a population of cells that exhibit chromatin condensation but are not $\mathrm{TH}$ immunoreactive; these are highlighted by the red arrows. Such nuclei are observed in control, $\mathrm{MPP}^{+}$-treated, and $\mathrm{MPP}^{+}$- and zVAD-fmk-treated cultures. These profiles may reflect a population of non-dopaminergic cells in the culture that are undergoing cell death, perhaps as a result of a change in the medium on the cultures.

To visualize activated caspase 3 in dopaminergic neurons after $\mathrm{MPP}^{+}$treatment, double-immunolabeling studies were performed using primary antibodies to activated caspase 3 and to TH. Cultures were grown for $5 \mathrm{~d}$, then returned to culture 

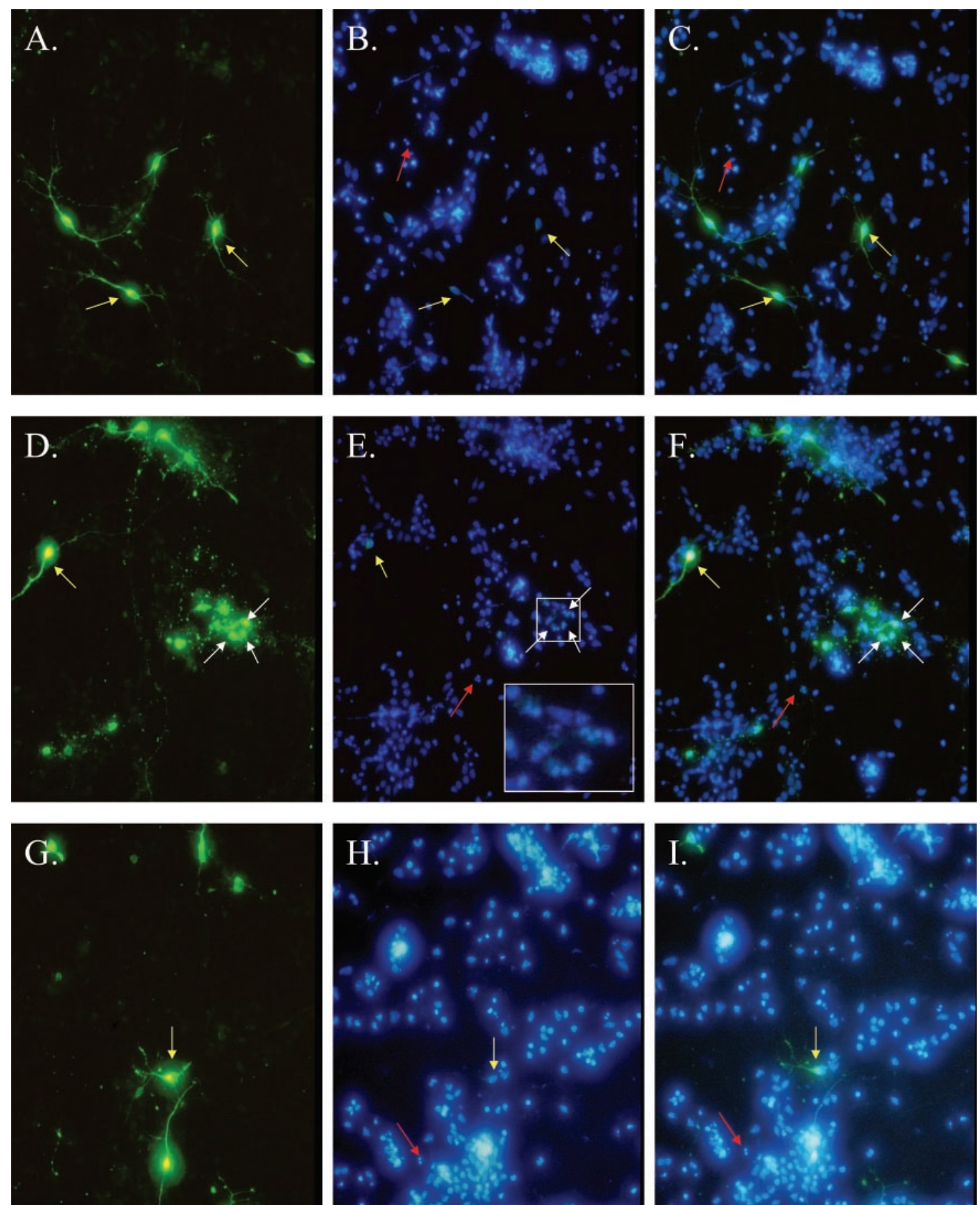

Figure 6. Colocalization of apoptotic nuclei with $\mathrm{TH}$ immunoreactivity in primary mesencephalic cultures after $\mathrm{MPP}^{+} \mathrm{exposure}^{\mathrm{C}} \mathrm{Cultures}$ were stained with a primary antibody raised against TH and visualized using FITC. Nuclei were visualized by counterstaining using Hoechst 33342 . $A-C$, Control cultures; $D-F$, cultures exposed to $10 \mu \mathrm{M} \mathrm{MPP}^{+}$for $48 \mathrm{hr} ; G-I$, cultures exposed to $10 \mu \mathrm{M} \mathrm{MPP}{ }^{+}$in the presence of $300 \mu \mathrm{M} \mathrm{zVAD-fmk}$. Each of the photomicrographs within a condition is of the same field of view, stained with tyrosine hydroxylase $(A, D, G)$ or Hoechst $33342(B, E, H)$ or dual exposed to show colocalization $(C, F, I)$. Apoptotic dopaminergic nuclei are shown by white arrows (and magnified in $E$, inset). Representative non-apoptotic dopaminergic nuclei are indicated by yellow arrows, and non-dopaminergic apoptotic nuclei by red arrows.

medium alone (Fig. $7 A-C$ ) or treated with $10 \mu \mathrm{M} \mathrm{MPP}{ }^{+}$for 24 hr (Fig. $7 D-F)$ or $48 \mathrm{hr}$ (Fig. $7 G-I)$. Figure 7, $A, D$, and $G$, shows TH immunoreactivity. Figure $7, B, E$, and $F$, shows activated caspase 3 immunoreactivity in the same field of view, and Figure 7, $C, F$, and $G$, shows colocalization of caspase 3 with TH immunoreactivity.

In control cultures, a number of TH-immunoreactive neurons can be observed (Fig. 7A), along with a population of cells expressing activated caspase 3 (Fig. $7 B$ ); however, there is little coexpression of activated caspase 3 with $\mathrm{TH}$ in these cultures (Fig. $7 C$ ), indicating that caspase 3 is not active in dopaminergic neurons. In cultures treated with $\mathrm{MPP}^{+}$for 24 or $48 \mathrm{hr}$, however, a population of dopaminergic neurons that coexpress $\mathrm{TH}$ and caspase 3 is apparent (Fig. $7 F, I$ ). In all treatment groups, a 

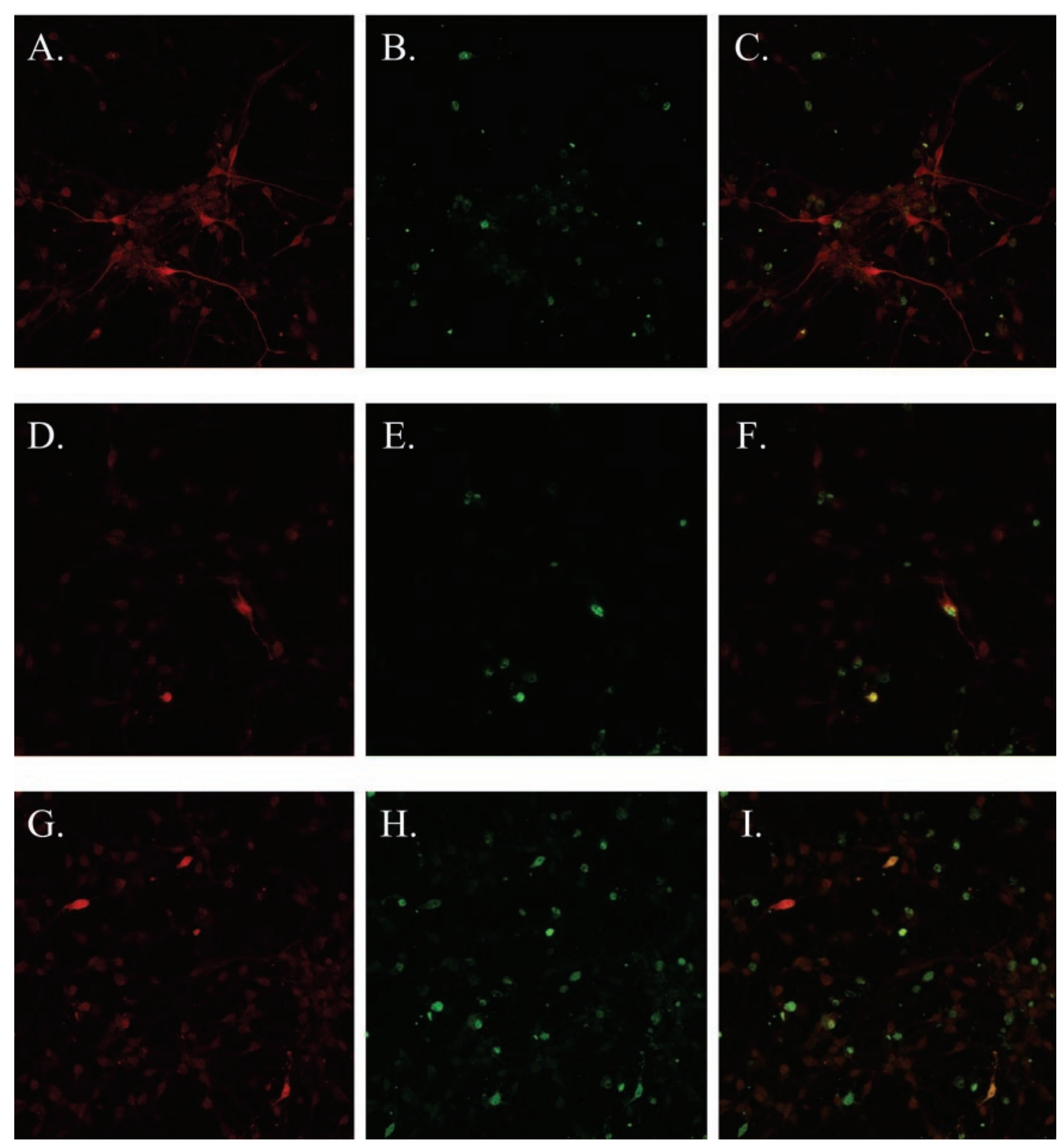

Figure 7. TH-immunoreactive neurons exposed to $10 \mu \mathrm{M} \mathrm{MPP}{ }^{+}$for 24 or $48 \mathrm{hr}$ express activated caspase 3. Cultures were treated with MPP ${ }^{+}$for the required time, then fixed and double immunostained using a monoclonal tyrosine hydroxylase antibody and a polyclonal antibody raised against active caspase 3. $A-C$, Control cultures; $D-F$, cultures treated with $10 \mu \mathrm{M} \mathrm{MPP}+$ for $24 \mathrm{hr} ; G-I$, cultures exposed to $\mathrm{MPP}^{+}$for 48 hr. $A, D$, and $F$ show immunostaining using an antibody to $\mathrm{TH} ; B, E$, and $H$ show the same field of view stained with the activated caspase 3 antibody. Colocalization of these antibodies is shown in $C, F$, and $I$.

population of non-dopaminergic neurons that express activated caspase 3 is apparent, indicating that there is a population of cells within the cultures undergoing apoptosis; this is in accordance with the presence of apoptotic profiles in a population of nondopaminergic neurons observed in Figure 6. Thus, $\mathrm{MPP}^{+}$treatment of primary cultures of dopaminergic neurons for 24 or $48 \mathrm{hr}$ causes activation of caspase 3 in these neurons.

To quantify the $\mathrm{MPP}^{+}$-induced caspase activation and chromatin condensation, a triple-labeling experiment was performed. Cultures were treated with $\mathrm{MPP}^{+}$for $48 \mathrm{hr}$ in the presence or absence of $300 \mu \mathrm{M}$ zVAD-fmk or the caspase 3 inhibitor M-791, then fixed and double immunostained for active caspase 3 and TH. Nuclei were counterstained using Hoechst 33342, and quantification was performed. Ten fields of view containing at least three TH-immunoreactive cells were quantified in each of three independent wells. The total number of nuclei was established, and the number of these that showed apoptotic features was established. The number of TH-immunoreactive neurons and the number of active caspase-3 neurons were also counted. Each field of view was quantified for the number of neurons coexpressing $\mathrm{TH} /$ active caspase 3 and $\mathrm{TH} /$ condensed chromatin. These data are shown in Figure 8. In Figure 8A, the number of apoptotic cells and the number of active caspase 3-immunoreactive cells in each treatment group are shown, expressed as a percentage of the total number of cells within the cultures. In control cultures there is a population of $\sim 20 \%$ of cells that express apoptotic morphology, likely as a result of stress through changing the medium or a natural attrition of cells within the culture. There is a slight 

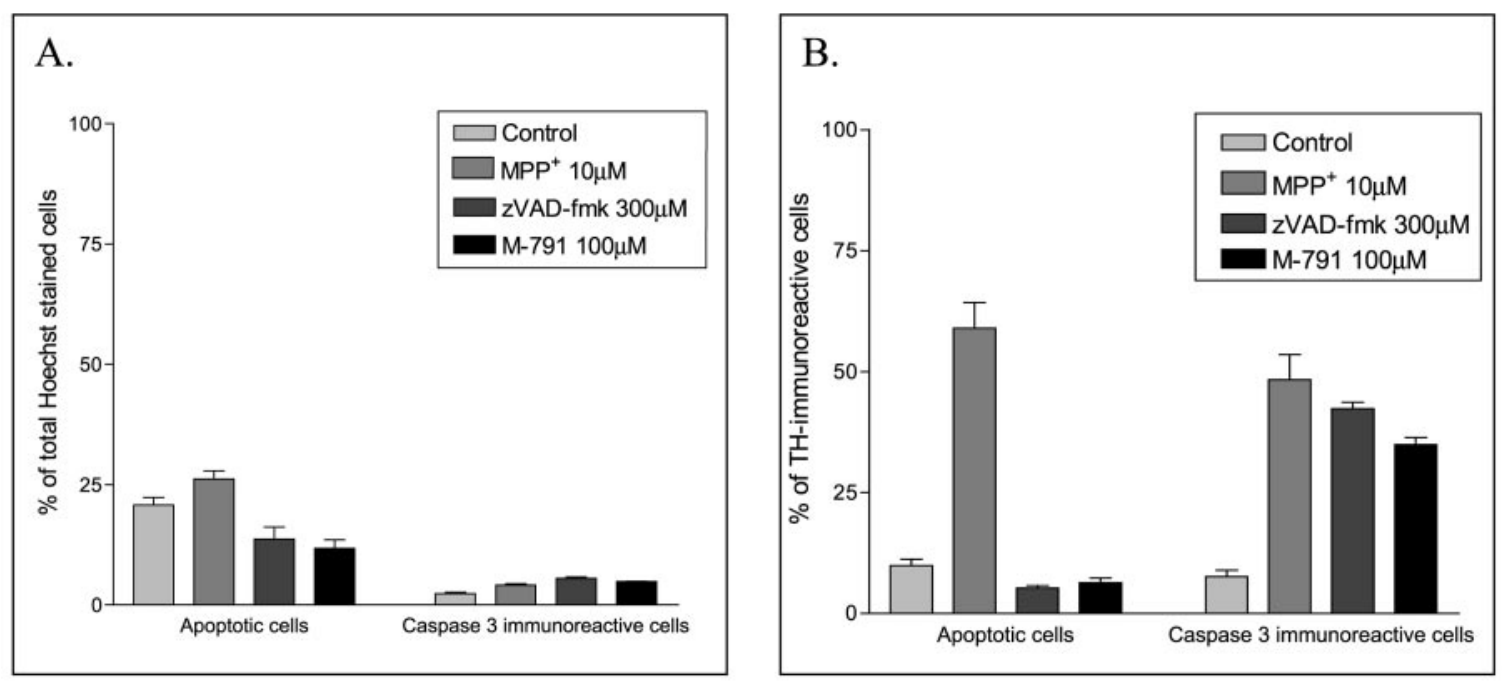

Figure 8. Effects of $\mathrm{MPP}^{+}$treatment in the presence and absence of caspase inhibition on the number of apoptotic profiles and active caspase 3 immunoreactive cells. Cells were double labeled for TH and active caspase 3, and the nuclei were counterstained with Hoechst 33342 . Cells were visualized using a $20 \times$ objective, and the total number of nuclei, the number of apoptotic nuclei, the number of TH-immunoreactive cells, and the number of active caspase 3-immunoreactive cells were quantified, together with the number of cells coexpressing TH and apoptotic nuclei, and TH and active caspase 3. Ten fields of view were quantified in each of three wells per treatment group. Cultures that were quantified were untreated control cultures, cultures exposed to $10 \mu \mathrm{M} \mathrm{MPP}{ }^{+}$for $48 \mathrm{hr}$, or cultures exposed to $10 \mu \mathrm{M} \mathrm{MPP}{ }^{+}$for $48 \mathrm{hr}$ in the presence of either $300 \mu \mathrm{M} \mathrm{zVAD}$-fmk or 100 $\mu \mathrm{M}$ M-791. $A$ shows the expression of apoptotic profiles and active caspase 3 as a percentage of the total cell population. $B$ shows the cells coexpressing either activated caspase 3 or apoptotic profiles with TH expressed as a percentage of the total number of TH-immunoreactive cells.

increase in the number of apoptotic cells in the $\mathrm{MPP}^{+}$-treated group that is reduced by the caspase inhibitors. There is also a small population $(<10 \%)$ of active caspase 3 -immunoreactive cells within control cultures. This is increased by $\mathrm{MPP}^{+}$treatment, but this increase is not reversed by the caspase inhibitors. Figure $8 B$ shows the expression of apoptotic nuclei and active caspase 3 in TH-immunoreactive neurons. Approximately $10 \%$ of TH-immunoreactive neurons have apoptotic nuclei in control cultures; this is markedly increased by $\mathrm{MPP}^{+}$treatment, which increases the number of apoptotic nuclei in the remaining $\mathrm{TH}-$ immunoreactive neurons to $\sim 60 \%$. Both of the caspase inhibitors that were tested completely reverse the increase in apoptotic nuclei induced by $\mathrm{MPP}^{+}$. When coexpression of $\mathrm{TH}$ and activated caspase 3 was examined, there was again a marked increase in the number of coexpressing cells, from $\sim 10 \%$ in control cultures to $\sim 50 \%$ in $10 \mu \mathrm{M} \mathrm{MPP}^{+}$-treated cultures. When $\mathrm{MPP}^{+}$ was coadministered with the caspase inhibitors, however, there was little decrease in the expression of activated caspase 3 in TH-immunoreactive neurons. This lack of decrease with the caspase inhibitors is likely attributable to the mode of action of the inhibitors, which bind to the cleavage site of the active caspase and prevent cleavage of cellular substrates rather than preventing formation of the active caspase from the inactive zymogen. Thus, in the inhibitor and $\mathrm{MPP}^{+}$-treated dopaminergic neurons, the caspase appears to be activated as in cultures treated with $\mathrm{MPP}^{+}$ alone, but inhibition prevents it from executing the apoptotic response; this leads to the decreased evidence of chromatin condensation and the increased neuronal number.

Not all $\mathrm{MPP}^{+}$-treated dopaminergic cells visualized expressed chromatin condensation or active caspase 3 ; this may reflect a population that has not yet effected the apoptotic response after $\mathrm{MPP}^{+}$treatment. At $48 \mathrm{hr}$ treatment, only $\sim 50 \%$ of dopaminergic cells remain in the cultures compared with untreated controls. Dopaminergic cells expressing active caspase 3 were also present within the cultures at earlier time points. It is likely that these cells that activate caspase 3 earlier in the time course undergo apoptosis and detach from the substratum, resulting in this decrease in numbers, and that the number of dopaminergic neurons counted with the active enzyme at $48 \mathrm{hr}$ underestimates the number of neurons that express this over the total treatment period.

\section{DISCUSSION}

Although $\mathrm{MPP}^{+}$is a commonly used model for selective dopaminergic neuronal cell death in vitro (Sanchez Ramos et al., 1986; Michel et al., 1989; Michel et al., 1990; Beck et al., 1991), reports conflict regarding the cell death mechanism. Apoptosis has been shown in vivo in the substantia nigra of MPTP-treated mice (Tatton and Kish, 1997; Eberhardt et al., 2000), depending on the dosing regimen used (Jackson-Lewis et al., 1995). In vitro, apoptosis has been demonstrated after $\mathrm{MPP}^{+}$treatment in rat mesencephalic-striatal cocultures (Mochizuki et al., 1994), in dissociated cultures of cerebellar granule cells and mesencephalic dopaminergic neurons (Dipasquale et al., 1991; Du et al., 1997; Dodel et al., 1998), and in the SH-SY5Y neuronal cell line (Fall and Bennet, 1998). In contrast, however, Lotharius and coworkers (1999) found no evidence for apoptosis in $\mathrm{MPP}^{+}$-treated rat mesencephalic neurons. $\mathrm{MPP}^{+}$treatment of dopaminergic MN9D cells also failed to produce evidence of apoptotic markers (Choi et al., 1999). The evidence for and against a role of apoptosis in $\mathrm{MPP}^{+}$toxicity is reviewed by Nicotra and Parves (2000); it appears most likely that the differences in types of cell death observed by different groups are dependent on the severity of the insult or the culture conditions that are used.

Here we show that $\mathrm{MPP}^{+}$treatment of primary dopaminergic neurons causes apoptosis and that caspase inhibition with zVADfmk prevents the $\mathrm{MPP}^{+}$-mediated loss of dopaminergic neurons. The number of surviving dopaminergic neurons in $10 \mu \mathrm{M} \mathrm{MPP}^{+}$ treated cultures decreased to $\sim 50 \%$, with zVAD-fmk restoring numbers to $\sim 90 \%$, confirming several previous reports. zVAD- 
fmk has been reported to attenuate $\mathrm{MPP}^{+}$toxicity in cerebellar granule neurons (Du et al., 1997) and mesencephalic dopaminergic neurons (Dodel et al., 1998; Eberhardt et al., 2000). In this study, zVAD-fmk increased the number of $\mathrm{MPP}^{+}$-treated dopaminergic neurons and the somatic size of these neurons after 48 hr; increased TH-immunoreactive cell number was observed up to $5 \mathrm{~d}$ after coadministration of the compounds (data not shown). zVAD-fmk was less effective at preventing the $\mathrm{MPP}^{+}$-mediated loss of $\left[{ }^{3} \mathrm{H}\right] \mathrm{DA}$ uptake, with significant increases only at $300 \mu \mathrm{M}$. Only a partial restoration of the neurite length of these neurons was observed, indicating that the dopamine transporter sites may not be spared. These data are similar to reported studies with both $\mathrm{MPP}^{+}$(Eberhardt et al., 2000) and 6-OHDA (Von Coelln et al., 2001), in which little neurite or [ $\left.{ }^{3} \mathrm{H}\right] \mathrm{DA}$ uptake restoration was observed with zVAD-fmk. Although these data and reports from other groups indicate an important role for caspases in mediating $\mathrm{MPP}^{+}$toxicity, a number of groups have found conflicting effects. Lotharius et al. (1999) found no protection from $\mathrm{MPP}^{+}$toxicity with another broad-spectrum caspase inhibitor, Boc-Asp-fmk, and zVAD-fmk did not protect dopaminergic MN9D cells from $\mathrm{MPP}^{+}$toxicity (Choi et al., 1999). Hartmann et al. (2001) reported that $\mathrm{MPP}^{+}$treatment induced apoptosis in primary dopaminergic neurons, but that caspase inhibition potentiated cell death by increasing necrosis, an effect that has been reported previously in other cell types (Lemaire et al., 1998); this effect was reversed if cultures were grown in elevated glucose. Thus, reports conflict regarding the efficacy of caspase inhibition in preventing $\mathrm{MPP}^{+}$toxicity in vitro.

In this study, caspase inhibition clearly promotes survival of dopaminergic neurons. Caspases can be divided into three families on the basis of structure and function; these families typically are involved in the inflammatory response, caspase activation, and execution of apoptosis, respectively (for review, see Nicholson and Thornberry, 1997; Stennicke and Salvesen, 1998). To determine which specific caspases mediate the toxicity, peptide inhibitors of specific caspases were tested; partial neuroprotection was observed with inhibitors of caspases 2,3 , and 9, but not with an inhibitor of caspase 1 . A novel caspase 3 inhibitor had neuroprotective effects equivalent to either zVAD-fmk or another broad-spectrum caspase inhibitor, M-920.

Coadministration of dopaminergic neurons with $\mathrm{MPP}^{+}$and the selective caspase 3 inhibitor M-791 caused almost complete protection of TH-immunoreactive neurons in vitro. The protection obtained with this compound was similar to that obtained with either of the broad-spectrum caspase inhibitors tested, zVAD-fmk or M-920, and greater than with the peptide inhibitor zDEVD-fmk. That the effects were mediated by caspase inhibition is indicated by the lack of effect of M-725, a structural analog of M-920 lacking activity at caspases. These data provide compelling evidence that in dopaminergic neurons exposed to $\mathrm{MPP}^{+}$ in vitro, inhibition of caspase 3 alone is sufficient to protect the neurons. Inhibition of caspase 3 with M-791 also decreased to control levels the number of apoptotic dopaminergic cells, a response similar to that of zVAD-fmk. In contrast, neither of these inhibitors prevented an $\mathrm{MPP}^{+}$-mediated increase in the number of $\mathrm{TH}$-immunoreactive cells expressing activated caspase 3. A likely explanation for this is that the inhibitors do not prevent cleavage and activation of the caspase zymogen but rather bind to the active site of the activated caspase to prevent substrate cleavage.

Caspase 3 is involved in the execution of apoptosis in a number of neuronal cell types after a range of insults. In vivo, caspase 3 inhibition attenuates damage after ischemia (Ma et al., 1998) and axotomy of retinal ganglion neurons (Kermer et al., 1998). In vitro, caspase 3 inhibition protects cerebellar granule neurons from $\mathrm{K}^{+}$deprivation-induced apoptosis (Ni et al., 1997) and PC12 cells from 6-hydroxydopamine toxicity (Ochu et al., 1998; Lotharius et al., 1999). Caspase 3 is activated by a range of factors, including caspase 9 . Caspase 9 is activated during release of cytochrome $c$ from mitochondria; the released cytochrome $c$ forms a complex with cytoplasmic APAF-1 and caspase 9 in the presence of ATP and activates caspase 9 (Liu et al., 1996; Zou et al., 1997). Activated caspase 9 then cleaves and activates caspase 3, leading to the apoptotic death of the cell (Li et al., 1997; Cai et al., 1998; Pan et al., 1998). Cytochrome $c$ release into the cytoplasm of cerebellar granule cells has been shown after $\mathrm{MPP}^{+}$ treatment (Du et al., 1997). Inhibition of caspase 9 using zLEHDfmk significantly increased survival of $\mathrm{MPP}^{+}$-treated $\mathrm{TH}$ immunoreactive neurons, indicating that this pathway may indeed be activated in $\mathrm{MPP}^{+}$toxicity.

Because the specificity of the caspase 2 inhibitor is suspect, it is possible that the effects observed with this inhibitor are mediated through inhibition of another caspase such as caspase 3. There is evidence in vivo that caspase 2 may be involved in MPTP toxicity; mice overexpressing $\mathrm{Bcl}-2$ are resistant to MPTP toxicity, with decreased expression of active caspase 2 after MPTP treatment compared with wild-type animals (Yang et al., 1998). More selective inhibitors may allow further clarification of the role of this caspase.

No effects were observed with the caspase 1 inhibitor zYVAD$\mathrm{cmk}$, consistent with previous reports in primary dopaminergic neurons (Dodel et al., 1998). These data, however, conflict with studies in transgenic mice overexpressing dominant negative caspase 1 that were resistant to MPTP toxicity in vivo (Klevenyi et al., 1999), and caspase 1 activation was observed in the dopaminergic cell line SN4741 after $\mathrm{MPP}^{+}$or oxidant treatment (Chun et al., 2001). Caspase 1 has been implicated as both a downstream target and an activator of caspase 8 , and caspase 8 inhibition has been shown to be protective against MPTP toxicity in mice in vivo, although not in vitro (Hartmann et al., 2001). Both caspase 3 and caspase 8 are expressed in the substantia nigra of Parkinson's disease patients (Hartmann et al., 2000, 2001). An explanation for the apparent conflict of these results may be that $\mathrm{MPP}^{+}$is capable of activating multiple caspase pathways depending on cellular conditions and that there may be a redundancy of function of some of these pathways under certain conditions.

The toxicity of $\mathrm{MPP}^{+}$for dopaminergic neurons under these conditions appears to be mediated by pathways that converge on activation of caspase 3 , and inhibition of caspase 3 is sufficient to spare at least the neuronal somata. The events before the caspase 3 activation are less clear. Caspase 9 inhibition provides partial neuroprotection, indicating that cytochrome $c$ release from mitochondria might be important. $\mathrm{MPP}^{+}$has been shown to open the mitochondrial permeability transition pore (PTP) in vitro (Cassarino et al., 1999), although inhibition of the mitochondrial PTP using cyclosporin A does not protect SH-SY5Y cells (Fall and Bennett, 1998) or mesencephalic dopaminergic neurons (data not shown). Cyclosporin A, however, is toxic at higher concentrations, so any potential neuroprotective effects may be masked. Another route of cytochrome $c$ release from mitochondria is through pores formed by pro-apoptotic members of the Bcl-2 family. Mice overexpressing Bcl-2 are resistant to MPTP toxicity in vivo and $\mathrm{MPP}^{+}$toxicity in vitro (Offen et al., 1998; Yang et al., 1998), so this may be a possible mechanism underlying the cell 
death. In addition to cytochrome $c$, other pro-apoptotic factors can be released from mitochondria in apoptosis, including second mitochondria-derived activator of caspase (SMAC)/direct IAP binding protein with low pI (DIABLO) and apoptosis-inducing factor (AIF). SMAC/DIABLO inhibits the activity of members of the IAP family, leading to caspase activation (Du et al., 2000; Verhagen et al., 2000). In this regard, it is interesting that adenoviral expression of X-chromosome-linked IAP protects nigral neurons from MPTP toxicity in mice in vivo (Eberhardt et al., 2000). No reports have been published as yet showing direct evidence for release of either SMAC/DIABLO or AIF. Further investigation may clarify the roles of mitochondrial factors in $\mathrm{MPP}^{+}$-induced apoptosis.

In conclusion, we show that caspase inhibition protects dopaminergic neurons from $\mathrm{MPP}^{+}$toxicity in vitro and that the caspases 2, 3, and 9, but not caspase 1, are involved in the pathway. The pathways activated by $\mathrm{MPP}^{+}$appear to converge on activation of caspase 3 , because inhibition of caspase 3 alone is sufficient to fully protect cells from $\mathrm{MPP}^{+}$-mediated cell death. Thus, the caspase cascade, or factors upstream regulating caspase activation, are targets for neuroprotective strategies in models of Parkinson's disease.

\section{REFERENCES}

Akaneya Y, Takahashi M, Hatanaka H (1995) Involvement of free radicals in $\mathrm{MPP}^{+}$neurotoxicity against rat dopaminergic neurons in culture. Neuroscience 193:53-56.

Beck KD, Knusel B, Pasinetti G, Michel PP, Zawadzka H, Goldstein M, Hefti F (1991) Tyrosine hydroxylase mRNA expression by dopaminergic neurons in culture: effect of 1-methyl-4-phenylpyridinium treatment. J Neurochem 57:527-532.

Bottenstein JE, Sato GH (1979) Growth of a rat neuroblastoma cell line in serum free medium. Proc Natl Acad Sci USA 76:514-517.

Cai J, Yang J, Jones DP (1998) Mitochondrial control of apoptosis: the role of cytochrome $c$. Biochim Biophys Acta 1366:139-149.

Cassarino DS, Parks JK, Parker Jr WD, Bennett Jr JP (1999) The Parkinsonian neurotoxin $\mathrm{MPP}^{+}$opens the mitochondrial permeability transition pore and releases cytochrome $c$ in isolated mitochondria via an oxidative mechanism. Biochim Biophys Acta 1453:49-62.

Choi W-S, Yoon S-Y, Oh TH, Choi E-J, O’Malley KL, Oh YJ (1999) Two distinct mechanisms are involved in 6-hydroxydopamine and $\mathrm{MPP}^{+}$induced dopaminergic neuronal cell death: role of caspases, ROS and JNK. J Neurosci Res 57:86-94.

Chun HS, Gibson GE, DeGiorgio LA, Zhang H, Kidd VJ, Son JH (2001) Dopaminergic cell death induced by MPP ${ }^{+}$, oxidant and specific neurotoxicant shares the common molecular mechanism. J Neurochem 76:1010-1021.

Degli EM (1998) Inhibitors of NADH-ubiquinone reductase: an overview. Biochim Biophys Acta 1364:222-235.

Dipasquale B, Marini AM, Youle RJ (1991) Apoptosis and DNA degradation induced by 1-methyl-4-phenylpyridinium in neurons. Biochem Biophys Res Commun 137:1442-1448.

Dodel RC, Du Y, Bales KR, Ling ZD, Carvey PM, Paul SM (1998) Peptide inhibitors of caspase-3-like proteases attenuate 1-methyl-4phenylpyridinum-induced toxicity of cultured fetal rat mesencephalic dopamine neurons. Neuroscience 86:701-707.

Du C, Fang M, Li Y, Li L, Wang X (2000) Smac, a mitochondrial protein that promotes cytochrome $c$-dependent caspase activation by eliminating IAP inhibition. Cell 102:43-53.

Du Y, Dodel RC, Bales KR, Jemmerson R, Hamilton Byrd E, Paul SM (1997) Involvement of a caspase-3-like cysteine protease in 1-methyl4-phenylpyridinium-mediated apoptosis of cultured cerebellar granule neurons. J Neurochem 69:1382-1388.

Eberhardt O, Coelin R, Kugler S, Lindenau J, Rathke-Hartlieb S, Gerhardt E, Haid S, Isenmann S, Gravel C, Srinivasan A, Bahr M, Weller M, Dichgans J, Schultz J (2000) Protection by synergistic effects of adenovirus-mediated X-chromosome-linked inhibitor of apoptosis and glial cell line-derived neurotrophic factor gene transfer in the 1-methyl4-phenyl-1,2,3,6-tetrahydropyridine model of Parkinson's Disease. J Neurosci 20:9126-9134.

Fall CP, Bennett Jr JP (1998) $\mathrm{MPP}^{+}$induced SH-SY5Y apoptosis is potentiated by cyclosporin A and inhibited by aristolochic acid. Brain Res 811:143-146.

Garcia CM, Peterson EP, Leiting B, Ruel R, Nicholson DW, Thornberry NA (1998) Inhibition of human caspases by peptide-based and macromolecular inhibitors. J Biol Chem 273:32608-32613.
Hartmann A, Hunot E, Michel P, Muriel M, Vyas S, Faucheux B, Mouatt-Prigent A, Turmel H, Srinivasan A, Ruberg M, Evan G, Agid Y, Hirsch E (2000) Caspase 3: a vulnerability factor and a final effector in the apoptotic death of dopaminergic neurones in Parkinson's Disease. Proc Natl Acad Sci USA 97:2875-2880.

Hartmann A, Troadec J-D, Hunot S, Kikly K, Faucheux B, MouattPrigent A, Ruberg M, Agid Y, Hirsch E (2001) Caspase-8 is an effector in apoptotic death of dopaminergic neurons in Parkinson's disease, but pathway inhibition results in neuronal necrosis. J Neurosci 21:2247-2255.

Hotchkiss RS, Chang KC, Swanson PE, Tinsley KW, Hui JJ, Klendre P, Xanthoudakis S, Roy S, Black C, Grimm E, Aspiotis R, Han Y, Nicholson DW, Karl IE (2000) Caspase inhibitors improve survival in sepsis: a critical role of the lymphocyte. Nat Immunol 1:496-501.

Jackson-Lewis V, Jakowec M, Burke RE, Przedborski S (1995) Time course and morphology of dopaminergic neuronal death caused by the neurotoxin 1-methyl-4-phenyl-1,2,3,6-tetrahydropyridine. Neurodegeneration 4:257-269.

Kermer P, Klocker N, Labes M, Bahr M (1998) Inhibition of CPP32-like proteases rescues axotomized retinal ganglion cells from secondary cell death in vivo. J Neurosci 18:4656-4662.

Klevenyi P, Andreassen O, Ferrante R, Schleicher Jr J, Friedlander R, Flint Beal M (1999) Transgenic mice expressing a dominant negative mutant interleukin-1 $\beta$ converting enzyme show resistance to MPTP toxicity. NeuroReport 10:635-638.

Lemaire C, Andreau K, Souvannavong V, Adam A (1998) Inhibition of caspase activity induces a switch from apoptosis to necrosis. FEBS Lett 425:266-270.

Li P, Nijhawan D, Budihardjo I, Srinivasula SM, Ahmad M, Alnemri ES, Wang X (1997) Cytochrome $c$ and dATP-dependent formation of APAF-1/caspase 9 complex initiates an apoptotic protease cascade. Cell 91:479-489.

Liu X, Kim CN, Yang J, Jemmerson R, Wang X (1996) Induction of apoptotic program in cell-free extracts: requirement for dATP and cytochrome $c$. Cell 86:147-157.

Lotharius J, Dugan LL, Malley KL (1999) Distinct mechanisms underlie neurotoxin-mediated cell death in cultured dopaminergic neurons. J Neurosci 19:1284-1293.

Ma J, Endres M, Moskowitz MA (1998) Synergistic effects of caspase inhibitors and MK-801 in brain injury after transient focal cerebral ischaemia in mice. Br J Pharmacol 124:756-762.

Marsden CD (1990) Neurophysiology. In: Parkinson's disease (Stern GM, ed), pp 57-98. London: Chapman and Hall Medical.

Michel PP, Dandapani BK, Sanchez Ramos J, Efange S, Pressman BC, Hefti F (1989) Toxic effects of potential environmental neurotoxins related to 1-methyl-4-phenylpyridinium on cultured rat dopaminergic neurons. J Pharmacol Exp Ther 248:842-850.

Michel PP, Dandapani BK, Knusel B, Sanchez Ramos J, Hefti F (1990) Toxicity of 1-methyl-4-phenylpyridinium for rat dopaminergic neurons in culture: selectivity and irreversibility. J Neurochem 54:1102-1109.

Mochizuki H, Nakamura N, Nishi K, Mizuno Y (1994) Apoptosis is induced by 1-methyl-4-phenylpyridinium ion $\left(\mathrm{MPP}^{+}\right)$in ventral mesencephalic-striatal co-culture in rat. Neurosci Lett 170:191-194.

Ni B, Wu X, Du Y, Su Y, Hamilton-Byrd E, Rockey PK, Rosteck Jr P Poirer GG, Paul SM (1997) Cloning and expression of a rat brain interleukin-1 $\beta$-converting enzyme (ICE)-related protease (IRP) and its possible role in apoptosis of cultured cerebellar granule neurons. J Neurosci 17:1561-1569.

Nicholson DW, Thornberry NA (1997) Caspases: killer proteases. Trends Biochem Sci 22:299-306.

Nicotra A, Parves SH (2000) Cell death induced by MPTP, a substrate for monoamine oxidase B. Toxicology 153:157-166.

Ochu EE, Rothwell NJ, Waters CM (1998) Caspases mediate 6-hydroxydopamine-induced apoptosis but not necrosis in PC12 cells. J Neurochem 70:2637-2640.

Offen D, Beart PM, Cheung NS, Pascoe CJ, Hochman A, Gorodin S, Melamed E, Bernard R, Bernard O (1998) Transgenic mice expressing human Bcl-2 in their neurons are resistant to 6-hydroxydopamine and 1-methyl-4-phenyl-1,2,3,6-tetrahydropyridine neurotoxicity. Proc Natl Acad Sci USA 95:5789-5794.

Pan G, Humke EW, Dixit VM (1998) Activation of caspases triggered by cytochrome c in vitro. FEBS Lett 426:151-154.

Sanchez Ramos J, Barrett JN, Goldstein M, Weiner WJ, Hefti F (1986) 1-Methyl-4-phenylpyridinium $\left(\mathrm{MPP}^{+}\right)$but not 1-methyl-4-phenyl1,2,3,6-tetrahydropyridine (MPTP) selectively destroys dopaminergic neurons in cultures of dissociated rat mesencephalic neurons. Neurosci Lett 72:215-220.

Schapira AHV (1998) Human complex I defects in neurodegenerative diseases. Biochim Biophys Acta 1364:261-270.

Stennicke HR, Salvesen GS (1998) Properties of the caspases. Biochim Biophys Acta 1387:17-31.

Tatton NA, Kish SJ (1997) In situ detection of apoptotic nuclei in the substantia nigra compacta of 1-methyl-4-phenyl-1,2,3,6-tetrahydropyridine-treated mice using terminal deoxynucleotidyl transferase labelling and acridine orange staining. Neuroscience 77:1037-1048. 
Thornberry NA, Rano TA, Peterson EP, Rasper DM, Timkey T, Garcia CM, Houtzager VM, Nordstrom PA, Roy S, Vaillancourt JP, Chapman KT, Nicholson DW (1997) A combinatorial approach defines specificities of members of the caspase family and granzyme B. Functional relationships established for key mediators of apoptosis. J Biol Chem 272:17907-17911.

Turmel H, Hartmann H, Parain K, Douhou A, Srinivasan A, Agid Y, Hirsch E (2001) Caspase 3 activation in 1-methyl-4-phenyl-1,2,3,6tetrahydropyridine (MPTP)-treated mice. Mov Disord 16:185-189.

Verhagen AM, Ekert PG, Pakusch M, Silke J, Connolly LM, Reid GE, Moritz RL, Simpson RJ, Vaux DL (2000) Identification of DIABLO, a mammalian protein that promotes apoptosis by binding to and antagonizing IAP proteins. Cell 102:42.
Von Coelln R, Kugler S, Bahr M, Weller M, Dichgans J, Schulz J (2001) Rescue from death but not from functional impairment: caspase inhibition protects dopaminergic cells against 6-hydroxydopamine-induced apoptosis but not against the loss of their terminals. J Neurochem 77:263-273

Yang L, Matthews RT, Schulz JB, Klockgether T, Liao AW, Martinou J, Penney JBJ, Hyman BT, Beal MF (1998) 1-Methyl-4-phenyl-1,2,3,6tetrahydropyride neurotoxicity is attenuated in mice overexpressing Bcl-2. J Neurosci 18:8145-8152.

Zou H, Henzel WJ, Liu X, Lutschg A, Wang X (1997) Apaf-1, a human protein homologous to $C$. elegans CED-4, participates in cytochrome $c$-dependent activation of caspase-3. Cell 90:405-413. 